\title{
Optimal nutrition: vitamin A and the carotenoids
}

\author{
David I. Thurnham* and Christine A. Northrop-Clewes \\ Northern Ireland Centre for Diet and Health, University of Ulster, Coleraine BT52 1SA, UK
}

\begin{abstract}
There are two major dietary sources of vitamin A: easily absorbed retinyl palmitate in foods of animal origin, and poorly bioavailable carotenoids from plant foods. Plasma retinol is tightly controlled, probably by regulation of retinol-binding protein (RBP) formation in the liver, and only hormonal factors (e.g. oral contraceptives) and infection will alter the homeostasis. Delivery of retinol to the tissues is facilitated by the RBP-retinol complex; however, there is evidence that this mechanism can be bypassed when very high doses of vitamin A are given. Some retinyl ester may be released to tissues from chylomicrons when the latter bind to tissue lipoprotein receptors during their passage from the gut to the liver following a meal. High-dose vitamin A therapy is a means of rapidly improving vitamin A status in persons with sub-optimal vitamin A nutrition but there are dangers of toxic symptoms (e.g. teratogenicity) from excess vitamin A usage. Evidence is presented to suggest that the plasma retinol: RBP may be a guide to optimal vitamin A status, since values less than one frequently occur in less-developed countries and during infection. In contrast to plasma retinol, plasma carotenoids reflect the dietary intake of plant foods. However, absorption is limited by poor bioavailability and a saturable uptake mechanism in competition with other phytochemicals. Recent work on bioavailability suggests that the calculation of plant food vitamin A activity should be re-examined. Illness has little influence on plasma levels except by suppressing appetite. Carotenoids are generally regarded as non-toxic yet intervention studies with $\beta$-carotene in smokers have been associated with increased lung cancer and heart disease. Some carotenoids are important as vitamin A precursors, but the physiological importance of their antioxidant properties is not known and consequently the amount needed for optimal nutrition is uncertain.
\end{abstract}

Vitamin A: Retinol: Retinoic acid: Carotenoids: $\beta$-Carotene

As many of the other papers presented at the present symposium indicate, optimal nutrition is difficult to define, hence 'nutritional adequacy' has been the target of the regulatory bodies charged with defining nutritional needs and/or nutritional requirements of human subjects for specific nutrients. Optimal nutrition has been regarded as a somewhat nebulous concept. For vitamin A, the minimum amount needed to prevent clinical symptoms was determined from various experimental and human studies and after adding an amount to cover possible extremes within the healthy population, amounts of the order $450-850 \mu \mathrm{g}$ retinol equivalents/d have been proposed as appropriate to meet the needs of most healthy persons within the specific population groups.

\section{Equivalency of $\beta$-carotene and retinol}

Vitamin A occurs as retinyl esters in foods of animal origin and in the form of provitamin A carotenoids in plant foods.
The term retinol equivalent (RE) indicates that vitamin $\mathrm{A}$ can be obtained from several sources; $1 \mu \mathrm{g}$ RE is equivalent to $1 \mu \mathrm{g}$ retinol (see Fig. 1) or 3.33 IU (a term which is now redundant, although still used). The retinyl esters are believed to be as bioavailable as retinol, hence a simple adjustment based on molecular weight gives the appropriate amounts of specific esters equivalent to $1 \mu \mathrm{g}$ RE. Thus, $1.83 \mu \mathrm{g}$ retinyl palmitate is also equivalent to $1 \mu \mathrm{g} \mathrm{RE}$. The provitamin A carotenoids are also important sources of vitamin A. The results of the 'Sheffield' studies carried out by the Medical Research Council during the Second World War provided important information to establish the relative equivalency of carotenoids and retinol (Hume \& Krebs, 1949). These and other studies suggested that $6 \mu \mathrm{g}$ $\beta$-carotene or $12 \mu \mathrm{g}$ other provitamin A carotenoids were equivalent to $1 \mu \mathrm{g}$ RE (Food and Agriculture Organization/World Health Organization, 1967). Poor absorption (30\% of dietary intake) and inefficient metabolism (during 
<smiles>CC1=C(/C=C/C(C)=C/C=C/C(C)=C/CO)C(C)(C)CCC1</smiles>

all-trans-Retinol

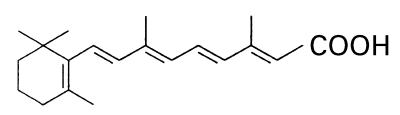

all-trans-Retinoic acid

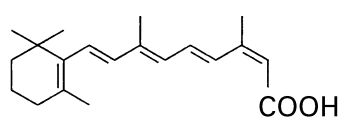

13-cis-Retinoic acid

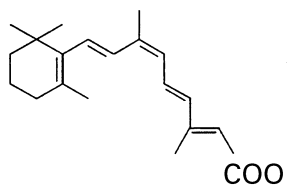

9-cis-Retinoic acid
Fig. 1. Structures of retinol, retinoic acid and retinoic acid metabolites, all-trans-retinoic acid and 9-cis-retinoic acid.

asymmetric metabolism of the carotenoid molecule to produce retinol $50 \%$ of $\beta$-carotene, or $75 \%$ of other carotenoids are lost) were the two major factors contributing to the poor bioavailability of the provitamin A carotenoids. Recent evidence suggests that these two factors should be re-examined, since evidence indicates that the metabolism of carotenoids is more efficient than previously thought. Two recent studies which re-examined the metabolic efficiency of the $\beta$ carotene 15, 15'-dioxygenase (EC 1.13.11.21) enzyme activity in rat (Devery \& Milborrow, 1994) and porcine (Nagao et al. 1997) small intestinal tissues found that the molar conversion of $\beta$-carotene to retinol was much closer to a ratio of 2 than previously obtained; i.e. one molecule of $\beta$-carotene should yield two molecules of retinol (central (symmetric) cleavage) and not one molecule as is currently assumed. If this is true for human subjects, the absorption of carotenoids must be even poorer than the $30 \%$ previously assumed. A lower absorption of $\beta$-carotene, e.g. $15 \%$ would support some of the recent observations of De Pee et al. (1995) who suggest that the current conversion factor overstates the bioavailability of $\beta$-carotene from vegetables.

\section{Homeostasis}

Of all the vitamin micronutrients, vitamin $\mathrm{A}$ is the one over which the body exercises the most active homeostatic control. Circulating concentrations of retinol bear no relationship to dietary intake except when hepatic stores of retinol are grossly depleted. Feeding large intakes of retinol or retinyl esters to adult human volunteers has only a small effect on blood retinol during the immediate postprandial period, and usually has no demonstrable physiological effects unless the dose is very large (Willett et al. 1983). Thus, in the study of Willett et al. (1983) feeding $25000 \mathrm{IU}$ retinyl palmitate $(7.5 \mathrm{mg} \mathrm{RE})$ daily for 4 months to adults did not alter plasma retinol. This finding is in contrast to the effects of hormonal contraceptives where their use by a group of Thai women both in the presence $(0.93$ or $1.86 \mathrm{mg}$ $\mathrm{RE}$ daily for $7 \mathrm{~d}$ per month) and absence of supplementary vitamins was accompanied by an approximately twofold increase in serum retinol. The increase in serum retinol was evident at 4 months and was still present at 1 year, and was no greater in those subjects receiving the extra vitamin A than in those subjects who did not (Table 1; Amatayakul et al. 1989). However, despite the changes in serum retinol, vitamin A status, as measured at the end of the study by the relative dose-response test, was not different between any of the groups of women (Table 2). The relative doseresponse test indicates liver stores of retinol. If stores are depleted then any dietary retinol will be quickly mobilized and released into the circulation. Thus, an increase in circulating retinol of $20 \%$ or more following a challenge dose is an indication of low liver stores. As plasma retinol increased by more than $20 \%$ in only one of the subjects tested, these findings suggested that vitamin A status was satisfactory in all groups, irrespective of the low serum retinol in the control group who received the intrauterine contraceptive device (Tables 1 and 2). These findings indicate that adequate vitamin A status on the basis of the relative doseresponse test can be associated with a wide range of serum retinol concentrations, a range which presumably is optimal for the body's needs. Furthermore, plasma retinol levels are not influenced by large intakes of retinyl palmitate but can be influenced by hormonal factors.

\section{Bypassing homeostatic control of plasma retinol}

The tight homeostatic control on plasma retinol is operated within the liver. Most dietary vitamin A is transported from the gut via the chylomicrons to the liver, where it is directed

Table 1. Influence of oestrogen oral contraceptives on plasma retinol* (Modified from Amatayakul et al. 1989) (Mean values and standard deviations)

\begin{tabular}{|c|c|c|c|c|c|}
\hline \multirow[b]{2}{*}{ Treatment } & \multirow[b]{2}{*}{$n$} & \multicolumn{4}{|c|}{ Plasma retinol $(\mu \mathrm{mol} / \mathrm{l})$} \\
\hline & & Mean & SD & Mean & $\mathrm{SD}$ \\
\hline $\begin{array}{l}\text { Oral contraceptives for } 21 \mathrm{~d} \text { followed by multivitamins } \\
\text { (two capsules daily for } 7 \mathrm{~d} \text { ) }\end{array}$ & 29 & $1 \cdot 33$ & $0 \cdot 24$ & $2 \cdot 13$ & 0.42 \\
\hline $\begin{array}{l}\text { Oral contraceptives for } 21 \mathrm{~d} \text { followed by multivitamins } \\
\text { (one capsule daily for } 7 \mathrm{~d} \text { ) }\end{array}$ & 33 & $1 \cdot 40$ & 0.49 & $2 \cdot 15$ & $0 \cdot 70$ \\
\hline $\begin{array}{l}\text { Intrauterine contraceptive device with one capsule of } \\
\text { placebo daily }\end{array}$ & 19 & 0.94 & 0.31 & $1 \cdot 15$ & 0.38 \\
\hline
\end{tabular}

* Plasma retinol significantly increased in the three groups who received oral contraceptives, each capsule containing $0.15 \mathrm{mg}$ levonorgestrel and 0.03 mg ethinylestradiol (Schering Chemical, Thailand). Each multivitamin capsule contained $1700 \mu \mathrm{g}$ retinyl palmitate. 
Table 2. Lack of influence of 13 months of treatment with oestrogen-containing oral contraceptives and vitamin A on vitamin A status in Thai women using the relative dose-response (RDR) test

(Mean values and standard deviations)

\begin{tabular}{|c|c|c|c|c|c|c|c|}
\hline \multirow[b]{4}{*}{ Treatment ${ }^{*}$} & \multirow[b]{4}{*}{$\mathrm{n}$} & \multicolumn{6}{|c|}{ Plasma retinol and RDR before and 1 month after $68000 \mu \mathrm{g}$ retinyl palmitate } \\
\hline & & \multicolumn{3}{|c|}{ Before } & \multicolumn{3}{|c|}{ After } \\
\hline & & \multicolumn{2}{|c|}{ Plasma retinol $(\mu \mathrm{mol} / \mathrm{l})$} & \multirow[b]{2}{*}{$\mathrm{RDR}+(\%)$} & \multicolumn{2}{|c|}{ Plasma retinol $(\mu \mathrm{mol} / \mathrm{l})$} & \multirow[b]{2}{*}{$\operatorname{RDR} \dagger(\%)$} \\
\hline & & Mean & SD & & Mean & SD & \\
\hline $\begin{array}{l}\text { Oral contraceptives for } 21 \mathrm{~d} \text { followed by multivitamins } \\
\text { (two capsules daily for } 7 \mathrm{~d} \text { ) }\end{array}$ & 7 & 1.94 & 0.32 & $-15,+29 \ddagger$ & $2 \cdot 08$ & 0.23 & $-29,+8$ \\
\hline $\begin{array}{l}\text { Oral contraceptives for } 21 \mathrm{~d} \text { followed by multivitamins } \\
\text { (one capsule daily for } 7 \mathrm{~d} \text { ) }\end{array}$ & 12 & $2 \cdot 15$ & 0.69 & $-25,+8$ & $2 \cdot 04$ & 0.53 & $-22,+16$ \\
\hline $\begin{array}{l}\text { Oral contraceptives for } 21 \mathrm{~d} \text { followed by one capsule } \\
\text { of placebo daily for } 7 \mathrm{~d}\end{array}$ & 14 & $2 \cdot 20$ & 0.69 & $-10,+11$ & $2 \cdot 12$ & 0.34 & $-5,+13$ \\
\hline $\begin{array}{l}\text { Intrauterine contraceptive device with one capsule of } \\
\text { placebo daily }\end{array}$ & 6 & 1.21 & 0.40 & $0,+16$ & $1 \cdot 18$ & 0.43 & $0,+17$ \\
\hline
\end{tabular}

* Subjects were selected randomly at the end of study from the four treatment groups.

† The RDR test was done using a challenge dose of $450 \mu \mathrm{g}$ retinyl palmitate $(246 \mu \mathrm{g} \mathrm{RE})$ and plasma retinol was measured before and after $5 \mathrm{~h}$.

$\ddagger$ Only one subject (group 1, $29 \%$ ) had an RDR response suggesting abnormally low vitamin A status. There were no differences in plasma retinol or the RDR response before and after the treatments with the $68 \mathrm{mg}$ vitamin A supplement (Amatayakul et al. 1989).

back into the circulation coupled with retinol-binding protein (RBP) and transthyretin in a $1: 1: 1$ complex or to stellate cells in the liver for storage. Formation of the retinol-RBP complex is controlled by metabolic factors and by circulating concentrations of retinoic acid metabolites (Blomhoff, 1994). Delivery of retinol to the tissues is then controlled by the availability of the vitamin A-protein complex in the circulation; however, this control mechanism can be bypassed, since large doses of retinol do have metabolic effects in some individuals who have apparentlynormal vitamin A status. The mechanism is believed to be bypassed via the lipoprotein-receptor pathway which can take up retinol palmitate directly from the chylomicrons.

The secondary vitamin A uptake mechanism by tissues may explain the toxicity of vitamin A. Large doses of vitamin A are teratogenic, and while plasma retinol does not change in response to large supplements of retinyl palmitate (50 and $150 \mathrm{mg} \mathrm{RE}$ ), plasma levels of the retinoic acid metabolites, all-trans-retinoic acid and the teratogen 13-cis-retinoic acid (Fig. 1), are transiently increased mostly over the first $4 \mathrm{~h}$, but can reach concentrations more than eighty times baseline levels (Eckhoff \& Nau, 1990; Buss et al. 1994). Retinoic acid metabolites are the active forms of retinol at the nuclear level, and plasma concentrations are normally 300-500 times less than those of plasma retinol (Norum, 1993). Hence, large disturbances in retinoic acid metabolites may have major effects on cellular metabolism. It is interesting to note that similar amounts of retinyl palmitate (50-150 mg RE), fed as a food in the form of liver $(50-150 \mathrm{~g})$, produced far smaller increases in retinoic acid metabolites which were only four to five times baseline levels (Buss et al. 1994).

The large increase in retinoic acid metabolites following the administration of vitamin A supplements has proved useful in the treatment of some diseases. Some patients with acute myeloid leukaemia respond to very large doses of alltrans-retinyl palmitate of the order of $52 \mu \mathrm{mol}(50000 \mathrm{IU}$, $15 \mathrm{mg} \mathrm{RE}) / \mathrm{m}^{2}$ per d (Norum, 1993). Acute myeloid leukemia is a group of malignancies in which differentiation of bone-marrow myeloid progenitor cells is arrested at differ- ent stages. During normal differentiation the myeloid stem cells give rise to platelets, erythrocytes, granulocytes and monocytes or macrophages. All-trans-retinoic acid or 13-cis-retinoic acid in vitro will stop proliferation of the immature leukaemic cells at concentrations $(10 \mathrm{nmol} / \mathrm{l})$ similar to those found in vivo, and induce terminal differentiation of the granulocyte. However, only a limited number of patients respond to retinoic acid and the number decreases with time, but the use of oral all-trans-retinol is more successful. It is believed that some retinyl palmitate is taken up by the bone-marrow cells via the lipoproteinreceptor pathway from chylomicrons circulating in the plasma, and is converted to retinoic acid. The direct uptake of retinol from the chylomicrons following the high-dose treatment bypasses the normal control of vitamin A supply via the liver-RBP pathway, and consequently achieves higher local concentrations of retinoic acid metabolites. Normal differentiation of the myeloid cells is then stimulated by retinoic acid binding to retinoic acid receptors on DNA-response elements, inducing allosteric change to activate the promoter regions on target genes (Norum, 1993).

The retinoic acid-response elements on DNA respond to all-trans-retinoic acid, 9-cis-retinoic acid and 13-cisretinoic acid. The response to 13-cis-retinoic acid may be after its conversion to all-trans-retinoic acid. In addition, a second class of response elements, RXR, respond to 9-cisretinoic acid and other ligands. Dimers of the receptor molecules are necessary to activate the DNA, and heterodimers are sometimes inhibitory (Blomhoff, 1994). It has also been shown that receptor molecules for thyroid hormone and vitamin D are very similar to the retinoic acidresponse elements. The retinoic acid isomers are the forms of vitamin A controlling most of the systemic effects of the vitamin in embryogenesis, morphogenesis, growth and differentiation etc. (Blomhoff, 1994), and of course are the main teratogenic metabolites (Klug et al. 1989; Hathcock et al. 1990; Buss et al. 1994). The normal concentration of retinoic acid in the circulation is approximately $4-6 \mathrm{nmol} / \mathrm{l}$ (Norum, 1993; Buss et al. 1994). Presumably concentrations of retinoic acid are low because of the high metabolic 
activity of these compounds, and toxic effects of high doses of vitamin A may be linked to the ability of small amounts of retinol to bypass normal control mechanisms and enter cells directly from retinyl esters in the chylomicrons. Retinyl esters are not normally found in fasting blood, but have been reported in amounts one to three times the normal concentration of plasma retinol in subjects showing clinical evidence of vitamin A toxicity (Smith \& Goodman, 1976). The tolerance to high doses of vitamin A varies between individuals and increases with age. Acute hypervitaminosis in infants and young children is usually associated with amounts in excess of $60 \mathrm{mg}$ RE (200000 IU), although infants below 12 months should not be given more than one or two daily amounts of $30 \mathrm{mg}$ RE (100000 IU). Daily amounts of this order in adults may take 6-108 months before the appearance of toxic signs (Bauernfeind, 1980). It would appear that the developing embryo is more vulnerable, and teratogenic effects of vitamin $\mathrm{A}$ in man have been associated with a single supplement of $150 \mathrm{mg}$ RE (500 $000 \mathrm{IU})$ in the first 2 months or $7.5 \mathrm{mg}$ RE (25 $000 \mathrm{IU})$ daily throughout pregnancy (Bernhardt \& Dorsey, 1974; Hathcock et al. 1990).

Vitamin A is normally administered orally, but topical application of metabolites have also proved useful in the control of skin disorders such as acne (Jones, 1984; Anonymous, 1988). 13-cis-Retinoic acid is one of the retinoids which has proved particularly useful by its ability to alter the development of the sebaceous glands, reducing excretion of sebum and the size of the glands. Unfortunately, the compounds are teratogenic and have long halflives. Etretinate is a modified ethyl ester of all-trans-retinoic acid. It has a half-life of $90 \mathrm{~d}$ and can still be detected 1 year after long-term therapy (Jones, 1984).

\section{Dietary retinol for the neonate and preschool child}

It cannot be said that the effects of large doses of retinol which act by transiently increasing the levels of retinoic acid isomers, are optimal, except in those disease situations where 'normal' vitamin A status appears to be ineffective such as in acute myeloid leukaemia or severe acne. Large doses of retinol and its esters are a useful tool to reduce morbidity and mortality in deficient children (Glasziou \& Mackerras, 1993), and the ability to rapidly influence the nutritional deficiency may well also be due to uptake of retinyl palmitate by the lipoprotein-receptor pathway. However, low-dose amounts of supplementary retinol in community studies are also effective (Muhilal et al. 1987; Rahmathullah et al. 1990). Infants are born with very low reserves of vitamin A and are vulnerable to vitamin A deficiency. They must acquire retinol from breast-milk in order to both grow and lay down reserves for the weaning period. Supporting growth and other metabolic functions takes priority in the distribution of vitamin A supplies. Nevertheless, to overcome the intermittent nature of vitamin A intake, it is essential to build up vitamin A stores in the liver. Liver reserves act as a buffer to maintain the levels of circulating retinol during periods of depletion. The liver contains the main store of vitamin A and operates on the principle of 'last in first out' (Batres \& Olson, 1987; Harrison et al. 1995). This process probably occurs because retinyl palmitate transported from the gut to the liver by the chylomicrons, is taken up by parenchymal cells before being transferred to stellate cells for more long-term storage. Nascent RBP is present in the parenchymal cells particularly during a period of deficiency, and will bind to any incoming retinol. The release of retinol bound to RBP into the circulation quickly follows an increase in dietary retinol if vitamin A status is poor. This principle is used in the retinol doseresponse test, where a larger proportion of a loading dose of retinol appears in the circulation of the deficient individual by comparison with the sufficient individual.

\section{Impact of infection on plasma retinol homeostasis}

Plasma retinol levels, as indicated previously, are well maintained against large variations in dietary intake, and as the Thai data indicated (Table 1) satisfactory liver vitamin A concentrations are associated with some relatively low plasma retinol concentrations which still appear to be optimal for health. Most of the Thai women had plasma retinol values below 1.6-1.8 $\mu \mathrm{mol} / \mathrm{l}(\mathrm{mean}+1 \mathrm{SD})$. However, with the onset of infection, plasma retinol concentrations are reduced and there is evidence that circulating levels may be suboptimal. Suboptimal vitamin A nutrition is associated with increased morbidity and mortality, thus a 'vicious circle' situation is stimulated by infection. Infection reduces plasma retinol which in turn appears to increase susceptibility to infection. Such a situation is not optimal and liver vitamin A stores, although adequate, may be unavailable because of depressed RBP synthesis. How should this situation be recognized and treated?

Infection or trauma will reduce plasma retinol (Louw et al. 1992) very rapidly, and this is believed to be mainly via a stimulation of the acute-phase response. The synthesis of both RBP (Rosales et al. 1996) and transthyretin (Ramsden et al. 1978) are depressed by infection. These proteins combine to transport retinol in the plasma as a fairly large molecular complex. Thus, the amount of retinol released into the circulation decreases (Thurnham, 1997). The fall in circulating retinol may be a protective measure to prevent urinary losses of retinol or of the retinol-RBP complex, since in the absence of transthyretin the size of the complex is such that it is more easily lost in the urine, especially in severe infection (Stephensen et al. 1994). Some studies done several years ago on Thai patients with malaria indicate the sort of falls in plasma retinol to expect on infection (Table 3; Thurnham \& Singkamani, 1991). The important point to notice about these findings is that the reduction in plasma retinol was similar irrespective of the starting plasma concentrations. Plasma retinol concentrations in subjects who were city dwellers and of a higher socioeconomic status than the rural group fell into a range which was low but not associated with any of the signs of vitamin A deficiency. In contrast, those subjects starting with low plasma retinol ended up with plasma levels in the 'risk' category for vitamin A deficiency. It is generally accepted that individuals with concentrations of retinol below $0.7 \mu \mathrm{mol} / 1$ are more likely to have impaired epithelial structure and integrity in the eye (Chowdhury et al. 1996) and recent findings suggest this situation may also be the same in the gut (Northrop-Clewes et al. 1998). In addition, con- 
centrations of plasma retinol between 0.7 and $1.6 \mu \mathrm{mol} / 1$ will not be optimal in the presence of infection. The contraceptive study reported earlier (Tables 1 and 2) indicated that individuals with such levels are not vitamin A deficient, but with the onset of infection plasma retinol can fall to levels which may be inadequate to maintain tissue integrity (see Table 3).

One possible way of detecting suboptimal concentrations of plasma retinol may be to measure retinol:RBP in the circulation. On release from the hepatocytes retinol is bound to RBP in a $1: 1$ molar ratio, and in healthy Western volunteers a retinol:RBP value of approximately 1 is usually observed (Kanai et al. 1968). In contrast, in Third World environments the corresponding value is frequently $<1$ and is observed to fall still further during infection. Table 4 shows the retinol:RBP values in Indian children whose blood values were measured before, during and 8 weeks after a measles infection. During the infection the mean retinol:RBP fell to $0 \cdot 37$, and at no time did mean values indicate adequate nutritional status (Reddy et al. 1986). The low value during infection may indicate both increased utilization of retinol by the tissues as well as insufficient release of retinol by the liver. Such values suggest suboptimal vitamin A status.

\section{Factors controlling plasma carotenoids}

Plasma carotenoid concentrations are not under the same metabolic control as that displayed by plasma retinol. Certain features, e.g. the higher concentrations of the provitamin A carotenoids in women than men, suggest some form of metabolic control (Thurnham, 1994), but plasma levels respond very quickly to changes in dietary intake and the circulating concentration is directly related to the amount in the diet (Willett et al. 1983; Brown et al. 1989; Micozzi et al. 1992). As already indicated, absorption of carotenoids from different food sources is poor and influenced by a variety of lifestyle factors, so correlation coefficients between intake and blood concentrations are usually low (Brady et al. 1996). Pure carotenoids in capsules are absorbed more easily, but even so the proportion absorbed inversely relates to intake and plasma levels reach a plateau within 10-20d (Micozzi et al. 1992). In addition, the plateau level achieved is strongly correlated with the previous plasma levels $(r 0.64, P<0.001$; Albanes et al. 1992), suggesting that individuals display a specific response to dietary carotenoids operating over a large concentration range.

In order to define optimal nutrition for carotenoids, biological roles of carotenoids have to be defined against those functional concentrations that can be compared. A small number of carotenoids function as a source of vitamin $\mathrm{A}$, of which $\beta$-carotene is the principal representative, but clearly-defined roles for other carotenoids have still to be identified. Epidemiological evidence in the USA suggests that lycopene intake may be protective against prostate cancer (Giovannucci et al. 1995), but plasma levels of lycopene are particularly low in many Third World countries, for example, China (Yang et al. 1984), India (Das et al. 1996), Pakistan (Thurnham et al. 1997) and Thailand (Thurnham et al. 1990), and these are not known to have an especially high risk of prostate cancer. Lutein and zeaxanthin have been shown to be consistently present in the retinal pigment epithelium of the eye (Bone et al. 1985,

Table 3. Influence of malaria infection on plasma retinol in rural and urban patients and matched control subjects (Data from Thurnham \& Singkamani, 1991)

\begin{tabular}{|c|c|c|c|c|c|c|}
\hline \multirow[b]{2}{*}{ Group } & \multirow[b]{2}{*}{$\mathrm{n}$} & \multicolumn{3}{|c|}{ Plasma retinol $(\mu \mathrm{mol} / \mathrm{l})$} & \multicolumn{2}{|c|}{ Control median minus patient median } \\
\hline & & Median* & Minimum & Maximum & Difference & Difference as \% control \\
\hline Rural patients $†$ & 21 & 0.5 & $0 \cdot 1$ & $1 \cdot 2$ & 0.64 & 56 \\
\hline Control subjects (accompanying relative)‡ & 20 & $1 \cdot 14$ & 0.17 & $2 \cdot 15$ & & \\
\hline Urban patients§ & 24 & $1 \cdot 17$ & 0.61 & 2.97 & 0.59 & 34 \\
\hline Control subjects (university and hospital staff) $\ddagger$ & 27 & $1 \cdot 76$ & 0.66 & $3 \cdot 33$ & & \\
\hline
\end{tabular}

* Median values were significantly different between groups (Kruskall-Wallis, $P<0.001$; group tests, $P<0.05$ ).

† All but one of the patients were male $(n 12)$ and female $(n 8)$ adult farmers infected with Plasmodium falciparum malaria.

$\ddagger$ Control subjects were matched by occupation where possible. Sex ratios were similar to the corresponding patient group.

$\S$ Patients comprised twenty men and four women who lived in Chiang Mai but travelled into the forest areas. Twelve of the grouphad $P$. vivax and ten had

P. falciparum.

Table 4. Plasma retinol : retinol-binding protein (RBP) in children before, during and after measles infection (Mean values with their standard errors)

\begin{tabular}{|c|c|c|c|c|c|}
\hline \multirow[b]{2}{*}{ Group ( $n 32 ;$ longitudinal data) } & \multicolumn{2}{|c|}{ Retinol‡ $(\mu \mathrm{mol} / \mathrm{l})$} & \multicolumn{2}{|c|}{$\mathrm{RBP} \ddagger(\mu \mathrm{mol} / \mathrm{l})$} & \multirow[b]{2}{*}{ Retinol : RBP } \\
\hline & Mean & SE & Mean & SE & \\
\hline Pre-measles & 0.58 & 0.06 & $1 \cdot 14$ & 0.06 & 0.51 \\
\hline Post-measles (8 weeks) & 0.67 & 0.06 & 1.09 & 0.07 & 0.61 \\
\hline
\end{tabular}

Mean values were significantly different from those for the pre-measles group:* $P<0.02$.

Mean values were significantly different from those for the post-measles group: $\dagger \dagger \dagger P<0.001$.

$\ddagger$ Recalculated from the original data of Reddy et al. (1986) using the molecular weights of 286 and 21000 for retinol and RBP respectively. 
1993) where they may act as antioxidants, improve visual acuity or protect against damaging photochemical reactions (Handelman et al. 1988; Bone et al. 1993). All carotenoids are antioxidants, but the specific location of just two carotenoids, lutein and zeaxanthin, in the eye (when all other tissues contain the full profile of carotenoids found in the blood) suggests there may be a specific requirement. It has been suggested that macular degeneration is a consequence of lutein and/or zeaxanthin inadequacy (Seddon et al. 1994), but this still remains to be established, and the level of dietary lutein and zeaxanthin needed for optimal visual function is not known.

\section{Absorption of $\beta$-carotene and its conversion to retinol}

When large doses of dietary $\beta$-carotene are supplied the plasma $\beta$-carotene response can vary tenfold (Van Vliet et al. 1995; O'Neill \& Thurnham, 1998). However, in two recent studies (Van Vliet et al. 1995; O'Neill \& Thurnham, 1998) in which very different large intakes of $\beta$-carotene were given (15 mg and $40 \mathrm{mg}$ respectively) the mean absorption of $\beta$-carotene was $<2.0 \mathrm{mg}$, suggesting that the human intestine possesses only a limited capacity to absorb $\beta$-carotene. In both studies more than half the $\beta$-carotene absorbed was converted to retinol. Less $\beta$-carotene was converted to retinol in our own study (37\%; O'Neill \& Thurnham, 1998) by comparison with that of the Dutch study (64\%; Van Vliet et al. 1995), but within individuals both the absorption of $\beta$-carotene and its conversion to retinol were remarkably constant. Three of the subjects in whom the difference in total uptake of $\beta$-carotene was almost threefold (161, 266 and $364 \mathrm{nmol} / \mathrm{h}$ per litre) consumed the $40 \mathrm{mg} \beta$-carotene dose under the same conditions on two occasions 4 months apart (O'Neill \& Thurnham, 1998). The total amount of $\beta$-carotene taken up by the chylomicron fraction on the two separate occasions did not differ by more than 3-6\%, and that of the retinyl palmitate formed by no more than 4-9\%. The dietary intake of $\beta$-carotene in the UK is approximately $2 \mathrm{mg} / \mathrm{d}$ (Gregory et al. 1990). Evidence suggests that absorbed $\beta$-carotene from intakes of this order is mostly converted to retinol (Goodman et al. 1966) and is reproducible (O’Neill \& Thurnham, 1998). High intakes of $\beta$-carotene are needed to increase plasma concentrations, and likewise when the intake is low the need to form retinol explains why very little $\beta$-carotene appears in the serum (Northrop-Clewes et al. 1996; Thurnham et al. 1997).

The factors determining the conversion of $\beta$-carotene and other provitamin A carotenoids to retinol are poorly understood. There would appear to be consistency within individuals both in the absorption of $\beta$-carotene and the amount of retinyl palmitate appearing in the chylomicron fraction. The absorption of $\beta$-carotene and lycopene was inversely related to the respective baseline concentrations $(r-0.66$ and -0.77 respectively; $P<0.05)$, although the relationship for lutein did not reach significance $(r-0 \cdot 5)$. There were also strong correlations between the amount of retinol formed and the amount of $\beta$-carotene absorbed in both men and women ( $r \quad 0.62$ and 0.50 respectively; $P<0.001$; O'Neill, 1997). However, from a diet of mixed carotenoids there will be both interaction in the uptake and transport of carotenoids into the enterocyte and competition between the carotenoids for metabolism by the dioxygenase. Van Vliet et al. (1996) recently reported on the relative potency for conversion to retinal of the main provitamin A carotenoids. They found that $\alpha$-carotene and $\beta$-cryptoxanthin were only 29 and $55 \%$ respectively as active as $\beta$-carotene in conversion to retinal, and that lutein and $\beta$-carotene competed but lycopene had no effect on the conversion. Other workers have also reported that carotenoids interact with one another during absorption. Kostic et al. (1995) reported that $\beta$-carotene depressed plasma lutein when the two carotenoids were fed together in equal amounts of approximately 15-20 mg. In contrast, lutein increased plasma $\beta$-carotene in five subjects but reduced it in three others. Recent work of our own also suggests that both lycopene $(53 \%)$ and lutein (38\%) may not be absorbed as efficiently as $\beta$-carotene $(\mathrm{P}<0.05$; Table 5; O’Neill \& Thurnham, 1998).

What is abundantly clear in all the previously mentioned studies is that the total amount of carotenoid taken up from the diet was relatively small, and it is clear that the gut has only a limited capacity to take up carotenoids from the diet. To optimize absorption, carotenoids need to be consumed regularly, but our knowledge regarding what carotenoid mixture may be optimal for the formation of retinol or any other carotenoid-related function is still in its infancy. The fact that gut metabolism is limited in the amount of carotenoid it can handle is also indicated by studies on gut mucosal cells recovered from stools. On normal diets the carotenoid content was small, but it increased when the subjects consumed carotenoid-rich vegetables for $5 \mathrm{~d}$ (Nair et al. 1996).

\section{Influence of sickness on carotenoid absorption}

There is no obvious or specific effect of illness on plasma carotenoid levels other than that attributable to loss of appetite. On exclusion of carotenoids from the diet $\beta$ carotene levels will tend to fall more rapidly than those of the other carotenoids, since its turnover of 11-15d (Micozzi et al. 1992) is shorter than that of lycopene (30 d) or lutein (60 d; Rock et al. 1992). Several plasma carotenoids are lower in smokers than non-smokers, even after controlling

Table 5. Area under the curve (AUC) concentrations (nmol/h per litre) of $\beta$-carotene, lycopene and lutein in the triacylglycerol-rich lipoprotein fraction following a standard meal† (Data from O'Neill \& Thurnham 1998)

\begin{tabular}{lccc}
\hline Carotenoid & $\beta$-Carotene & Lycopene & Lutein \\
\hline Dose $(\mathrm{mg})$ & 40 & 38 & 31 \\
AUC concentration: & & & \\
$\quad$ Median & 238 & $126^{*}$ & $91^{*}$ \\
Range & $174-382$ & $108-263$ & $56-139$ \\
$\% \beta$-Carotene value & & 53 & 38
\end{tabular}

Median AUC for both lycopene and lutein were significantly lower than that for $\beta$-carotene (ANOVA): ${ }^{*} P<0.05$. However, correction for the smaller amounts fed removed the significance in the case of lycopene but not lutein.

$\dagger$ The capsules used contained nominally $40 \mathrm{mg}$ of each of the carotenoids. The values shown were obtained by in-house analyses. Capsules were fed with a standard meal to six volunteers (three men and three women). Blood was collected hourly for $8 \mathrm{~h}$ to obtain AUC. Baseline data from blood values before the meal were subtracted from experimental values. 
for dietary intake (Thurnham, 1990, 1994), but in absorption studies to measure the absorption of $\beta$-carotene, lycopene and lutein under identical conditions only lutein was significantly less well absorbed in smokers compared with non-smokers (O’Neill, 1997).

Numerous studies have associated low plasma concentrations of $\beta$-carotene and some of the other carotenoids with increased health risks; for example, the consistent finding of low $\beta$-carotene in subjects who subsequently developed lung cancer (Connett et al. 1989). This finding was not entirely a smoking-related phenomenon, since most studies controlled for smoking in their analyses. However, in studies done on heavy smokers or asbestos-exposed workers supplements of $\beta$-carotene did not reduce the risk of lung cancer (The ATBC Cancer Prevention Study Group, 1994; Omenn et al. 1996). Likewise, in other high-risk groups supplements of $\beta$-carotene did not reduce the recurrence of skin cancer (Greenberg et al. 1990) or colon cancer (Greenberg et al. 1994). In contrast, several carotenoids have been shown to be protective against experimental cancers and to be active in cell-based systems. Carotenoids have important effects on immune cells and are capable of activating retinoic acid-response elements in vitro, although at higher concentrations than retinoic acid itself (International Agency for Research on Cancer Working Group, 1998). The importance of these functions of carotenoids in vivo is still uncertain, and much more work is required to determine the physiological significance and the optimal concentrations needed.

\section{Conclusions}

Vitamin A metabolism is tightly regulated. Plasma retinol is the main metabolite in the circulation, and its concentration is mainly controlled by factors influencing the availability of RBP in the liver. Retinol: RBP is approximately 1 in a well-nourished person. Lower values may be an indication of suboptimal status. Regulation of the supply of vitamin A to tissues can be bypassed by large oral doses of pure retinol or its esters. There are few advantages to this practice in most individuals. However, large oral doses do enable the rapid uptake of vitamin $\mathrm{A}$ in deficiency, but they also increase the risk of teratogenicity in pregnancy. Vitamin A can be supplied by provitamin A carotenoids, mainly $\beta$ carotene. The efficiency of this process varies widely between individuals, but preliminary evidence suggests that it is constant within individuals. There appears to be competition between the different carotenoids for absorption from mixtures of carotenoids. The importance of the nonprovitamin A carotenoids in physiological functions is still not known. Likewise the antioxidant properties of carotenoids per se, or their cancer-preventative properties in man, still require to be established before recommendations can be made for optimal dietary allowances.

\section{References}

Albanes D, Virtamo J, Rautalahti M, Haukka J, Palmgren J, Gref C-G \& Heinonen OP (1992) Serum beta-carotene before and after beta-carotene supplementation. European Journal of Clinical Nutrition 46, 15-24.
Amatayakul K, Underwood BA, Ruckphaopunt S, Singkamani R, Linpisarn S, Leelapat P \& Thanangkul O (1989) Oral contraceptives: effect of long-term use on liver vitamin A storage assessed by the relative dose response. American Journal of Clinical Nutrition 49, 845-848.

Anonymous (1988) Does topical Tretinoin prevent cutaneous ageing. Lancet i, 977-978.

Batres RO \& Olson JA (1987) A marginal vitamin A status alters the distribution of vitamin A among parenchymal and stellate cells in rat liver. Journal of Nutrition 117, 874-879.

Bauernfeind JC (1980) The Safe Use of Vitamin A. Washington, DC: International Vitamin A Consultative Group.

Bernhardt IB \& Dorsey DJ (1974) Hypervitaminosis A and congenital renal anomalies in a human infant. Obstetrics and Gynecology 43, 750-755.

Blomhoff R (1994) Vitamin A in Health and Disease. New York: Marcel Dekker.

Bone RA, Landrum JT, Hime GW, Cains A \& Zamor J (1993) Stereochemistry of the human macular carotenoids. Investigative Ophthalmology and Visual Science 34, 2033-2040.

Bone RA, Landrum JT \& Tarsis SL (1985) Preliminary identification of the human macular pigment. Vision Research 25, 1531-1535.

Brady WE, Mares-Perlman JA, Bowen P \& Stacewicz-Sapuntzakis M (1996) Human serum carotenoid concentrations are related to physiologic and lifestyle factors. Journal of Nutrition 126, 129137.

Brown ED, Micozzi MS, Craft NE, Bieri JG, Beecher G, Edwards BK, Rose A, Taylor PR \& Smith JCJ (1989) Plasma carotenoids in normal men after a single ingestion of vegetables or purified $\beta$-carotene. American Journal of Clinical Nutrition 49, 12581265.

Buss NE, Tembe EA, Predergast BD, Renwick AG \& George CF (1994) The tetratogenic metabolites of vitamin A in women following supplements and liver. Human and Experimental Toxicology 13, 33-43.

Chowdhury S, Kumar R, Ganguly NK, Kumar L, Nain CK \& Walia BNS (1996) Conjunctival impression cytology with transfer (CICT) to detect pre-clinical vitamin A deficiency among slum children in India. British Journal of Nutrition 75, 785-790.

Connett JE, Kuller LH, Kjelsberg MO, Polk BF, Collins G, Rider A \& Hulley SB (1989) Relationship between carotenoids and cancer. The multiple risk factor intervention trial (MRFIT) study. Cancer 64, 126-134.

Das BS, Thurnham DI \& Das DB (1996) Plasma $\alpha$-tocopherol, retinol and carotenoids in children with falciparum malaria. American Journal of Clinical Nutrition 64, 94-100.

de Pee S, West CE, Muhilal, Karyadi D \& Hautvast JGAJ (1995) Lack of improvement in vitamin A status with increased consumption of dark-green leafy vegetables. Lancet 346, 75-81.

Devery J \& Milborrow BV (1994) $\beta$-Carotene-15,15'-dioxygenase (EC 1.13.11.21) isolation reaction mechanism and an improved assay procedure. British Journal of Nutrition 72, 397-414.

Eckhoff C \& Nau H (1990) Vitamin A supplementation increases levels of retinoic acid compounds in human plasma: possible implications for teratogenesis. Archives of Toxicology 64, 502503.

Food and Agriculture Organization/World Health Organization (1967) Requirements of vitamin A, Thiamine, Riboflavine and Niacin. Report of a Joint FAO and WHO Expert Group. FAO Nutrition Meeting Report Series no. 41 and Technical Series WHO no. 362. Geneva: WHO.

Giovannucci E, Ascherio A, Rimm EB, Stampfer MJ, Colditz GA \& Willett WC (1995) Intake of carotenoids and retinol in relation to risk of prostate cancer. Journal of the National Cancer Institute 87, 1767-1776. 
Glasziou PP \& Mackerras DEM (1993) Vitamin A supplementation in infectious diseases: a meta-analysis. British Medical Journal 306, 366-370.

Goodman DS, Blomstrand R, Werner B, Huang HS \& Shiratory T (1966) The intestinal absorption and metabolism of vitamin A and $\beta$-carotene in man. Journal of Clinical Investigation 45, $1615-1623$.

Greenberg ER, Baron JA, Stukel TA, Stevens MM, Mandel JS, Spencer SK, Elias PM, Lowe N, Nierenberg DW, Bayrd G, Corwin Vance J, Freeman DHJ, Clendenning WE, Kwan T \& Skin Cancer Prevention Group (1990) A clinical trial of beta carotene to prevent basal-cell and squamous-cell cancers of the skin. New England Journal of Medicine 323, 789-795.

Greenberg ER, Baron JA, Tosteson TD, Freeman DH, Beck GJ, Bond JH, Colacchio TA, Coller JA, Frankl HD, Haile RW, Mandel JS, Nierenberg DW, Rothstein R, Snover DC, Stevens MM, Summers RW \& van Stolk RU (1994) A clinical trial of antioxidant vitamins to prevent colorectal adenoma. New England Journal of Medicine 331, 141-147.

Gregory JR, Foster K, Tyler H \& Wiseman M (1990) The Dietary and Nutritional Survey of British Adults. London: H.M. Stationery Office.

Handelman GJ, Dratz EA, Reay CC \& Van Kuijk JGM (1988) Carotenoids in the human macula and whole retina. Investigative Ophthalmology and Visual Science 29, 850-855.

Harrison EH, Gad MZ \& Ross AC (1995) Hepatic uptake and metabolism of chylomicron retinyl esters: probable role of membrane/endosomal retinyl ester hydrolase. Journal of Lipid Research 36, 1498-1506.

Hathcock JN, Hattan DG, Jenkins MY, McDonald JT, Sundaresan PR \& Wilkening VL (1990) Evaluation of vitamin A toxicity. American Journal of Clinical Nutrition 52, 183-202.

Hume EM \& Krebs HA (1949) Vitamin A Requirements of Human Adults. A Report of the Vitamin A Sub-Committee of the Accessory Food Factors Committee. Medical Research Council Special Report no. 264. London: H.M. Stationery Office.

International Agency for Research on Cancer Working Group (1998) Carotenoids. Lyon: WHO International Agency for Research on Cancer.

Jones DH (1984) Retinoids for skin disorders. Practitioner 228, 1043-1048.

Kanai M, Raz A \& Goodman DS (1968) Retinol binding protein: the transport protein for vitamin A in human plasma. Journal of Clinical Investigation 47, 2025-2044.

Klug S, Lewandowski C, Wildi E \& Neubert D (1989) All-trans retinoic acid and 13-cis retinoic acid in the rat whole embryo culture: abnormal development due to the all-trans isomer. Archives of Toxicology 63, 440-444.

Kostic D, White WS \& Olson JA (1995) Intestinal absorption, serum clearance, and interactions between lutein and $\beta$-carotene when administered to human adults in separate or combined doses. American Journal of Clinical Nutrition 62, 604-610.

Louw JA, Werbeck A, Louw MEJ, Kotze TJvW, Cooper R \& Labadarios D (1992) Blood vitamin concentrations during the acute-phase response. Critical Care Medicine 20, 934-941.

Micozzi MS, Brown ED, Edwards BK, Bieri JG, Taylor PR, Khachik F, Beecher GR \& Smith JC (1992) Plasma carotenoid response to chronic intake of selected foods and $\beta$-carotene supplements in men. American Journal of Clinical Nutrition 55, 1120-1125.

Muhilal, Permeisih D, Idjradinata YR, Muherdiyantiningsih \& Karyadi D (1987) Vitamin A-fortified monosodium glutamate and health, growth, and survival of children: a controlled field trial. American Journal of Clinical Nutrition 48, 1271-1276.

Nagao A, During A, Hoshina C, Terao J \& Olson JA (1997) Stoichiometric conversion of all trans $\beta$-carotene to retinal by pig intestinal extract. Archives of Biochemistry and Biophysics 328, 57-63.

Nair PP, Lohani A, Norkus EP, Feagins H \& Bhagavan HN (1996) Uptake and distribution of carotenoids, retinol and tocopherols in human colonic epithelial cells in vivo. Cancer Epidemiology, Biomarkers and Prevention 5, 913-916.

Northrop-Clewes CA, McCullough FSW, Das BS, Lunn PG, Downes RM \& Thurnham DI (1998) Improvements in vitamin A intake influence gut integrity in infants. XVIIIth International Vitamin A Consultative Group Meeting, March, pp. 101 Abstr. Washington, DC: ILSI Research Foundation.

Northrop-Clewes CA, Paracha PI, McLoone UJ \& Thurnham DI (1996) Impact of improved vitamin A status on response to iron supplements in Pakistani infants. American Journal of Clinical Nutrition 64, 694-699.

Norum KR (1993) Acute myeloid leukaemia and retinoids. European Journal of Clinical Nutrition 47, 77-87.

O’Neill ME (1997) Factors affecting carotenoid absorption and a comparative assessment of carotenoid intakes in five European countries. DPhil Thesis, University of Ulster.

O'Neill ME \& Thurnham DI (1998) Intestinal absorption of $\beta$ carotene, lycopene and lutein in men and women following a standard meal; response curves in the triacylglycerol-rich lipoprotein fraction. British Journal of Nutrition 79, 149-159.

Omenn GS, Goodman GE, Thornquist MD, Balmes J, Cullen MR, Glass A, Keogh JP, Meyskens FLJ, Valanis B, Williams JHJ, Barnhart S \& Hammer S (1996) Effects of a combination of beta carotene and vitamin A on lung cancer and cardiovascular disease. New England Journal of Medicine 334, 1150-1155.

Rahmathullah L, Underwood BA, Thulasiraj RD, Milton RC, Ramaswamy K, Rahmathullah R \& Babu G (1990) Reduced mortality among children in Southern India receiving a small weekly dose of vitamin A. New England Journal of Medicine 323, 929-935.

Ramsden DB, Prince HP, Burr WA, Bradwell AR, Black EG, Evans AE \& Hoffenberg R (1978) The inter-relationship of thyroid hormones, vitamin $\mathrm{A}$ and their binding proteins following acute stress. Clinical Endocrinology 8, 109-122.

Reddy V, Bhaskaram P, Raghuramulu N, Milton RC, Rao V, Madhusudan J \& Radha Krishna KV (1986) Relationship between measles, malnutrition, and blindness: a prospective study in Indian children. American Journal of Clinical Nutrition 44, 924-930.

Rock CL, Swenseid ME, Jacob RA \& McKee RW (1992) Plasma carotenoid levels in human subjects fed a low carotenoid diet. Journal of Nutrition 122, 96-100.

Rosales FJ, Ritter SJ, Zolfaghari R, Smith JE \& Ross AC (1996) Effects of acute inflammation on plasma retinol, retinol-binding protein, and its messenger RNA in the liver and kidneys of vitamin A sufficient rats. Journal of Lipid Research 37, 962-971.

Seddon AM, Ajani UA, Sperduto RD, Hiller R, Blair N, Burton TC, Farber MD, Gragoudas ES, Haller J, Miller DT, Yannuzzi LA \& Willett WC (1994) Dietary carotenoids, vitamin A, C, and E, and advanced age-related macular degeneration. Journal of the American Medical Association 272, 1413-1420.

Smith FR \& Goodman DS (1976) Vitamin A transport in human vitamin A toxicity. New England Journal of Medicine 294, 805808.

Stephensen CB, Alvarez JO, Kohatsu J, Hardmeier R, Kennedy JIJ \& Gammon RBJ (1994) Vitamin A is excreted in the urine during acute infection. American Journal of Clinical Nutrition 60, 388-392.

The ATBC Cancer Prevention Study Group (1994) The alphatocopherol, beta-carotene lung cancer prevention study: design, methods, participant characteristics, and compliance. Annals of Epidemiology 4, 1-9. 
Thurnham DI (1990) Anti-oxidant vitamins and cancer prevention. Journal of Micronutrient Analysis 7, 279-299.

Thurnham DI (1994) $\beta$-Carotene, are we misreading the signals in risk groups? Some analogies with vitamin C. Proceedings of the Nutrition Society 53, 557-569.

Thurnham DI (1997) Impact of disease on markers of micronutrient status. Proceedings of the Nutrition Society 56, 421-431.

Thurnham DI, Northrop-Clewes CA, Paracha PI \& McLoone UJ (1997) The possible significance of parallel changes in plasma lutein and retinol in Pakistani infants during the summer season. British Journal of Nutrition 78, 775-784.

Thurnham DI \& Singkamani R (1991) The acute phase response and vitamin A status in malaria. Transactions of the Royal Society of Tropical Medicine and Hygiene 85, 194-199.

Thurnham DI, Singkamani R, Kaewichit R \& Wongworapat K (1990) Influence of malaria infection on peroxyl-radical trapping capacity in plasma from rural and urban Thai adults. British Journal of Nutrition 64, 257-271.
Van Vliet T, Schreurs WHP \& Van Den Berg H (1995) Intestinal $\beta$-carotene absorption and cleavage in men: response of $\beta$-carotene and retinyl esters in the triglyceride-rich lipoprotein fraction after a single oral dose of $\beta$-carotene. American Journal of Clinical Nutrition 62, 110-116.

Van Vliet T, Van Schaik F, Schreurs WHP \& Van Den Berg H (1996) In vitro measurement of beta-carotene cleavage activity: methodological considerations and the effect of other carotenoids on beta-carotene cleavage. International Journal of Vitamin and Nutrition Research 66, 77-85.

Willett WC, Stampfer MJ, Underwood BA, Taylor JO \& Hennekens CH (1983) Vitamins A, E and carotene: effects of supplementation on their plasma levels. America Journal of Clinical Nutrition 38, 559-566.

Yang CS, Sun Y-H, Yang Q, Miller KW, Li G, Zheng S, Ershow AG, Blot WJ \& Li J-Y (1984) Vitamin A and other deficiencies in Linxian, a high esophageal cancer incidence area in Northern China. Journal of the National Cancer Institute 73, 1449-1453. 
https://doi.org/10.1017/S0029665199000592 Published online by Cambridge University Press 